\title{
Performance, ritual y movilización social. Primero de mayo y acción encapuchada en Santiago
}

\author{
Performance, Ritual, and Mobilization. May 1st and Hooded Action in Santiago
}

\author{
Nicolás Orellana Águila*
}

Resumen: Las manifestaciones son fenómenos recurrentes en la historia de Chile. Si bien profusamente estudiadas, se ha descuidado el análisis del enfrentamiento violento entre encapuchados y policía, a pesar de ser centrales en muchas manifestaciones. Esta acción persistente, invita a reflexionarla en términos simbólicos más que materiales. A través de la observación participante, este artículo avanza en la lectura de la acción encapuchada en su dimensión performativa, proponiendo interpretar el fenómeno como ritual, ya que revela valores culturales fundamentales a través de la performativización de una secuencia compleja de actos simbólicos.

Palabras clave: Encapuchados, enfrentamiento violento, manifestación contestataria, proceso ritual, performance.

\begin{abstract}
Contentious demonstrations have been recurrent in Chilean history. Although heavily studied, scholars have left aside the analyses of the violent confrontation between hooded persons [the encapuchados] and the police, which usually acquires a peculiar centrality in most of the demonstrations. This persistent action invites us to reflect on it in symbolic terms. This paper pretends, through participant observation, to advance in a performative understanding of this phenomenon, proposing an interpretation of hooded action as a ritual, since it reveals fundamental cultural values through the performing of a complex sequence of symbolic acts.
\end{abstract}

Keywords: Hooded persons, violent confrontation, contentious gathering, ritual process, performance

Recibido: 17 julio 2019 Aceptado: 3 octubre 2019

\footnotetext{
* Chileno, académico, Profesor Asociado Universidad Academia de Humanismo Cristiano; Profesor Universidad Bernardo O’Higgins; norellanaa@docentes.academia.cl; orellanani@docente.ubo.cl.
} 


\section{Introducción}

Los estudios de movilización social impulsan permanentemente debates que promueven la búsqueda de perspectivas que profundicen en las especificidades de los procesos contestatarios que emergen continuamente en la escena social y política. En Chile, la movilización social ha estado presente permanentemente en la actividad social y política a lo largo de la historia reciente, deviniendo un fenómeno central para poder comprender la experiencia de la sociedad contemporánea. Gran parte de las investigaciones que se centran en analizar estas movilizaciones, se basan sobre todo en los ciclos espectaculares de acción social y política contestataria (2006 y 2011), y en métodos indirectos de producción de información y conocimientos, se tornan insuficientes para entender la complejidad de la experiencia contestataria. ¿Qué sucede en el transcurso de un evento de protesta? ¿Existen escenificaciones y significaciones compartidas, múltiples, contradictorias, o aun superpuestas?, y isignifican o transmiten algo dichas performatividades?, son algunas de las preguntas que surgen una vez que se identificaron actores, formas de protesta, y formas de organización, y que invitan a sumergirse en la experiencia, encorporada, de la protesta social.

En el presente artículo propongo explorar la posibilidad de comprensión de uno de los aspectos más relevantes, pero menos estudiados, de los eventos de protesta en Chile. Se trata de lo que denomino acción encapuchada, una acción que es constitutiva de prácticamente todas las manifestaciones contestatarias relevantes, que es inherente a la protesta social en tanto tal y que, sin un adecuado tratamiento reflexivo en torno a ella, la comprensión de la contestación en Chile queda inconclusa.

La acción encapuchada forma parte del repertorio de protesta callejera entendida como violencia política popular. Si bien en la historia de esta acción se pueden encontrar episodios de reventones sociales durante todo el siglo $X X^{1}$, que recurren violencia revelando "una relación conflictiva entre el Estado, las élites dominantes y los sectores populares" 2 , la acción encapuchada es una acción que, en su forma contemporánea, se puede remontar hasta las luchas populares de resistencia antidictatorial de la década de 19803, debido a que, por razones de seguridad, debían encapucharse para luchar ${ }^{4}$. En este contexto, "la acción social revolucionaria, semilegal y clandestina, (...) se sostuvo,

\footnotetext{
${ }^{1}$ Gabriel Salazar, La violencia politica popular en las 'Grandes Alamedas'. La violencia en Chile 1947-1987 (Una perspectiva histórico popular), Santiago, LOM Ediciones, 2006 [1990].

${ }^{2}$ Raúl Zarzuri, Tamara Contreras, "Jóvenes y violencia. Los usos de la violencia y la construcción de la participación juvenil", Gloria de la Fuente, Sergio Contreras, Paulo Hidalgo, Julio Sau (eds.), Participación y nuevos desafíos político-institucionales, Santiago, LOM, 2009, 113-148, 129.

${ }^{3}$ Pedro Rosas, Rebeldía, subversión y prisión política. Crimen y castigo en la transición chilena, Santiago, LOM Ediciones, 2004.

${ }^{44}$ Juan Carlos Gómez, Los encapuchados, actores anticapitalistas de la posmodernidad neoliberal, Rebelión, 2016, http://www.rebelion.org/noticia.php?id=213339.
} 
domicilió y desarrolló (...) en espacios sociales preferentemente populares y juveniles" 5 , intensificándose en fechas emblemáticas como los 11 de septiembre, los 29 de marzo, o en las protestas nacionales de 1983-1986.

En este contexto, esta acción se debe considerar, primero, como un fenómeno cuya particularidad es que la realizan individuos o grupos que emergen de la misma manifestación, que tapan sus rostros con "capuchas", que consisten principalmente en poleras negras enrolladas, que dejan sólo los ojos al descubierto, y que se enfrentan violentamente con la policía. Esta acción se despliega generalmente en tres espacios: a) las fechas significativas para la historia de las luchas populares, como el 29 de marzo, Día del Joven Combatiente, o el 11 de septiembre, golpe de Estado de 1973; b) las acciones separadas espacialmente de eventos contestatarios, pero en el marco de una movilización convocante, como los cortes de calle previas o en el ocaso de jornadas de movilización, y; c) durante manifestaciones masivas de protesta, donde la acción encapuchada se despliega en sus intersticios, aunque siempre articulada a ellas. Su rasgo característico (la capucha), además de darles una homogeneidad estética basada en un tipo estándar de vestimenta, donde prima el color negro, el polerón con gorro, pantalón jeans y zapatillas deportivas, dificulta una adecuada caracterización de quienes la escenifican, si bien diversos estudios indican que se trata mayoritariamente de jóvenes urbano-populares, y de estudiantes secundarios y universitarios, en función del espacio en que se despliega su acción ${ }^{6}$. Lo que la observación directa de la manifestación permite inferir, es que en su mayoría se trata de jóvenes cuya distinción de género y de origen social es irrelevante para llevar a cabo la acción y que, si bien no constituyen el grueso de un evento contestatario, su particular despliegue performativo hace que devengan el centro de atención de las protestas. Además, se puede inferir a través de sus consignas, sus rayados en los muros, y de su despliegue performativo, que su identidad ideológica tiende más hacia una perspectiva anti sistémica amplia, donde confluyen una variedad de posiciones ideológicas radicales, que hacia una ideología exclusivamente anarquista, como suele pensarse, fundamentalmente debido a que, si bien es notorio que varios grupos de encapuchados se preparan de antemano, en muchas ocasiones se les suman individuos que, en el fragor de las manifestaciones, se encapuchan y engrosan el contingente de encapuchados, sin pertenecer ni responder a ninguna organización. Como dicen Zarzuri y Contreras, "Estas violencias políticas de nuevo tipo se enmarcan dentro de la práctica de la acción directa y se vinculan con un espacio amplio y diverso de jóvenes anticapitalistas, que se expresan de manera esporádica y, muchas veces espontánea, en manifestaciones aglutinadoras"7. Es una variedad de agrupaciones, individuos e ideologías lo que compone a este actor plural, más que un grupo identificable, una ideología clara, o un sujeto social en particular.

\footnotetext{
${ }^{5}$ Pedro Rosas, "Luka: Subversivo y rebelde de la transición chilena. Un ejercicio de Historia Oral y memoria", Raúl Zarzuri, Rodrigo Ganter, (Comp.), Jóvenes: la diferencia como consigna. Ensayos sobre la diversidad cultural juvenil, Santiago, Ediciones CESC, 2005, 239-261.

6 Tamara Contreras, "Los "11" en democracia: ¿vandalismo anómico o nueva radicalidad política juvenil?", Raúl Zarzuri, Rodrigo Ganter (comp.), Jóvenes: la diferencia como consigna. Ensayos sobre la diversidad cultural juvenil, Santiago, Ediciones CESC, 2005, 211-238; Rosas, op. cit., 2005; Zarzuri, op. cit., 2009.

${ }^{7}$ Zarzuri, op. cit., 2009, 124.
} 
En virtud de lo anterior, el objetivo aquí es mostrar cómo la acción encapuchada, íntimamente articulada a la manifestación pública, se constituye como rito, es decir, como la realización de una secuencia compleja de actos simbólicos, que revelan procesos culturales fundamentales ${ }^{8}$. La apuesta es proponer que esas performances adquieren el carácter de ritos de rebelión9, como actos simbólicos catárticos que, a través de sus haceres, sus materialidades y sus interacciones, transmiten significaciones que, aunque de modo contingente, tensionan el orden dominante. Hablar en términos rituales significa interesarse por las acciones eficaces convencionalizadas que obedecen a momentos de pasaje, cíclicos o de crisis social, y cuyas dimensiones simbólicas tienen fines prácticos, por medio de los cuales se revelan los valores del grupo ${ }^{10}$. Hablar de performances implica, por su parte, interesarse por lo que las personas hacen, y cómo muestran a otros lo que hacen para comunicar cosas ${ }^{11}$. En este sentido, relevar el carácter ritual y performativo de la acción encapuchada permite dar cuenta de dimensiones de una acción que no pueden explicarse ni haciendo referencia a explicaciones de tipo económico, como las desigualdades o la explotación, ni de tipo psicológico, como el carácter o desviaciones individuales. La acción encapuchada, de este modo, puede ser comprendida apelando a su dimensión cultural, porque busca expresar y transmitir valores e identidades12, e histórica, porque busca transmitir y actualizar memorias rebeldes y contrahegemónicas ${ }^{13}$.

Comprender la acción encapuchada como ritualidad es el objetivo del presente artículo, analizando su despliegue y escenificación durante el Primero de Mayo Clasista y Combativo, la manifestación de protesta más significativa, y que aglomera mayor diversidad de individuos y organizaciones contestatarias en el Chile contemporáneo. Lo que expongo aquí es el resultado de una investigación basada fundamentalmente en la observación participante que realicé en diversas manifestaciones entre 2015 y 2019,

\footnotetext{
${ }^{8}$ Victor Turner, On the Edge of the Bush. Anthropology as Experience, University of Arizona Press, Tucson, AZ, 1985; Monica Wilson, "Nyakyusa Ritual and Symbolism", American Anthropologist 56:2, 1954, 228241.

${ }^{9}$ Max Gluckman, "Rituals of Rebellion in South-East Africa", Max Gluckman, Order and Rebellion in Tribal Africa, London, Routledge; Susanne Schröter, "Rituals of Rebellion - Rebellion as Ritual: A Theory Reconsidered", Jens Kreinath, Constance Hartung, and Annette Deschner (eds.) The Dynamics of Changing Rituals. The Transformation of Religious Rituals within Their Social and Cultural Context, New York, Peter Lang Publishers, 2004, 41-57.

10 Catherine Bell, Ritual Theory, Ritual Practice, Oxford, Oxford University Press, 2009 [1992]; Victor Turner, El proceso ritual. Estructura y antiestructura, Madrid, Editorial Taurus, 1988 [1968]; Wilson, op. cit., 228-241.

11 Richard Schechner, Performance Theory, New York, Routledge, 2005 [1988]; Richard Schechner, Performance Studies: An Introduction, London, Routledge, 2013 [2002]; Diana Taylor, The Archive and the Repertoire. Performing Cultural Memory in the Americas. Durham, Duke University Press, 2003; Walter Imilan, "Performance", Dhan Zunino, Guillermo Giucci, y Paola Jirón (eds.), Términos clave para los estudios de movilidad en América Latina, Buenos Aires, Biblos, 2018, 147-152.

12 Jeffrey Juris, "Violence Performed and Imaginated. Militant Action, the Black Bloc and the Mass Media in Genoa" Critique of Anthropology 25:4, 2005, 413-432. DOI: https://doi.org/10.1177/0308275X05058657

13 Elizabeth Jelin, "Exclusión, memorias y luchas políticas", CLACSO, Estudios Latinoamericanos sobre cultura y transformaciones sociales en tiempos de globalización, Buenos Aires, CLACSO, 2005; Rosas, op. cit., 2005.
} 
poniendo especial atención a la del Primero de Mayo Clasista y Combativo, cuyos periodos de observación directa, breves e intensos, se constituyen como el principal material del que obtuve insumos para el presente artículo.

Empíricamente, mi interés por profundizar en la acción encapuchada comenzó mientras realizaba las entrevistas de mi investigación doctoral, centradas en la relevancia de la experiencia contestataria de activistas radicales. En ellas surgían de modo persistente referencias a la violencia y al encapuchamiento, por lo que comencé a observar con mayor detenimiento las dinámicas de diversas protestas en las que este despliegue fuese significativo, como las marchas conmemorativas del 11 de septiembre, las manifestaciones estudiantiles, laborales, ambientales, étnicas y feministas que se despliegan en Santiago. Pero fue la manifestación del Primero de Mayo Clasista y Combativo, que concentra una parte importante de las organizaciones más radicales del Chile contemporáneo, la que se tornó un escenario particularmente favorable para la observación, por lo que me dediqué los años siguientes ${ }^{14}$ a realizar observación participante sistemática de esta manifestación en particular, observando las interacciones entre diversos actores, sus ritmos ${ }^{15}$, performances 16 , y comunicación simbólica encorporada [embodied] ${ }^{17}$. La dinámica de la acción encapuchada en los espacios de manifestación masiva, es relativamente homogénea. La elección de la manifestación del Primero de Mayo Clasista y Combativo, a diferencia de otros estudios que describen y analizan esta acción durante la marcha del "11"18, o en la Facultad de Filosofía y Humanidades "un día de conmemoración de algún hecho doloroso ocurrido en nuestra historia reciente"19, tiene que ver con la intención de demostrar que la acción encapuchada, si bien está estrechamente vinculada a la memoria de luchas antidictatoriales, no se limita exclusivamente a ellas, desbordándola en un proyecto de rebelión. Además, con esta elección se pretende también mostrar que no es exclusivamente en las fechas conmemorativas donde se despliega esta acción, sino que permea todas las manifestaciones contestatarias. En este sentido, se observa con claridad en la marcha del Primero de Mayo clasista y combativo, que esta acción articula las dimensiones de memoria histórica popular, con proyectos políticos de transformación social.

\footnotetext{
${ }^{14}$ Entre los años 2015 y 2019 he realizado observación participante de una diversidad de marchas, poniendo particular atención a las del Primero de Mayo Clasista y Combativo. Este año 2019, además, realizamos etnografías colectivas de diversas marchas (8 de marzo, Primero de Mayo, de estudiantes, de profesores, de diversidad sexual, ambientales), con un equipo de cinco etnógrafas y etnógrafos, en el marco de un proyecto de investigación en curso. En total, el registro de observación se compone de más de veinte marchas, de las cuales cinco corresponden a las del primero de mayo clasista y combativo, lo que constituye un sustento previo y de mayor alcance a esta marcha, que emerge como un tipo ideal de manifestación.

${ }^{15}$ Henri Lefebvre, Rhythmanalysis. Space, time and everyday life, London, Continuum, 2004 [1992]; Dhan Zunino, "Ritmo/ritmoanálisis", Dhan Zunino, Guillermo Giucci, y Paola Jirón (eds.), Términos clave para los estudios de movilidad en América Latina, Buenos Aires, Biblos, 2018, 161-170.

16 Turner, op. cit. 1985; Imilan, op. cit. 2018.

17 Victor Turner, "Symbolic Studies", Annual Review of Anthropology 4, 1975, 145-161 ; David Le Breton, «Mauss et la naissance de la sociologie du corps » Revue du MAUSS 36: 2, 2010, 371-384.

${ }^{18}$ Contreras, op. cit. 2005

${ }^{19}$ Olga Grau, "El encapuchamiento de la memoria”, Nelly Richard (Ed.), Políticas y Estéticas de la Memoria, Santiago, Editorial Cuarto Propio, 2000, 199-204.
} 
Realicé observación participante asistiendo y acompañando, como un manifestante más, de las marchas, prestando especial atención a las dinámicas e interacciones, para luego hacer anotaciones descriptivas y reflexiones preliminares. En base a la sistematización de estas anotaciones, presento aquí el patrón de comportamiento de los encapuchados y lo que propongo presentar como su dimensión performativa y ritual.

Este artículo presenta la fase de trabajo de observación participante, basada en una descripción densa de la manifestación, y en particular de la acción encapuchada. En este sentido, tiene un enfoque etnográfico en su triple dimensión de técnica de investigación, encuadre metodológico, y como un tipo de escritura que relata "aspectos verídicos resultantes de una investigación empírica rigurosa" 20 , cuyo objeto es desentrañar las estructuras significativas, y las articulaciones existentes entre las prácticas sociales y sus significados para dar cuenta de la densidad de la vida social21. La descripción densa de las manifestaciones, permite explorar y profundizar el entendimiento de estas experiencias, dando cuenta de que es "a través de lo que hacen, o más bien a través de cómo lo hacen [que] anuncian a la sociedad que algo "otro" es posible" 22, con el potencial de tensionar las comprensiones ordinarias que se tejen en torno a ellas. El enfoque etnográfico, en este sentido, se torna particularmente ventajoso para poder dar cuenta del sentido de las reflexiones propuestas en este artículo, con miras a "desentrañar las lógicas simbólicas, morales o pragmáticas ocultas que subyacen en sus acciones" 23 . Además, en tanto enfoque etnográfico, se torna evidente la imposibilidad de reclamar una pretendida objetividad, más bien apelando a una perspectiva ubicua y situada del investigador, con miras a lograr una etnografía comprometida y colaborativa ${ }^{24}$.

Para lograr el propósito señalado, primero presento brevemente la discusión académica sobre el fenómeno de la acción encapuchada, que gira principalmente en torno a la idea de violencia política y criminalización mediática. Luego, describo las dinámicas de la marcha del Primero de Mayo Clasista y Combativo del año 2016, año que da cuenta de mejor manera que otros de las interacciones entre encapuchados, manifestantes, y policía, ya que los despliegues de esta acción se sitúan más claramente que otros años en los intersticios de la manifestación. Finalmente, para comprender este fenómeno, exploro la posibilidad de interpretarlo en tanto ritual, como una performatividad que transmite significados, identidades y valores culturales de modo endógeno para los encapuchados,

${ }^{20}$ Eduardo Restrepo, Etnografía. Alcances, técnicas y éticas, Lima, Fondo Editorial de la Universidad Nacional Mayor de San Marcos, 2018, 48.

${ }^{21}$ Clifford Geertz, La interpretación de las culturas, Barcelona, Gedisa, 2003 [1973]; David Graeber, Fragments of an Anarchist Anthropology, Chicag, Prickly Paradigm Press, 2004; Restrepo, op. cit.

${ }^{22}$ Alberto Melucci, "The Symbolic Challenge of Contemporary Movements", Social Research 52: 4, 1985, 789-816, 812.

${ }^{23}$ Graeber, op. cit., 11.

${ }^{24}$ Manisha Desai, "The Possibilities and Perils for Scholar-Activists and Activist-Scholars. Reflections on the Feminist Dialogues", Jeffrey Juris, Alex Khasnabish (eds.), Insurgent Encounters. Transnational Activism, Ethnography, \& the Political, Durham, Duke University Press, 2013, 89-107; Joanne Rappaport, "Beyond Participant Observation: Collaborative Ethnography as Theoretical Innovation" Collaborative Anthropologies 1, 2008, 1-31; Restrepo, op. cit., 2018. 
y exógeno, para el conjunto de contestatarios y sus adversarios, poniendo en tensión las interpretaciones dominantes, y abriendo una vía de interpretación al fenómeno en Chile, que no ha sido explorada sino en otras latitudes.

\section{Breve acercamiento al fenómeno de la acción encapuchada: violencia política y criminalización mediática}

En Chile, movimientos obreros, campesinos y de pobladores, así como luchas estudiantiles, identitarias, territoriales, ambientales y ciudadanas, han sacudido la historia social durante todo el siglo XX y lo que va del actual. Con altos y bajos, la protesta ha sido un elemento persistente de la cotidianidad social y política nacional. En este sentido, más que el despertar de una sociedad desmovilizada y despolitizada ${ }^{25}$, lo que se observa en Chile es la continuidad histórica de conflictos sociales que tienen expresión a través de la protesta pública.

Esta diversidad de eventos contestatarios, ciclos de protesta y movimientos sociales, ha suscitado una variedad de análisis e interpretaciones, donde una parte importante de ellos se centra en los grandes procesos de movilización que han irrumpido en la escena nacional, con impactos significativos en los ámbitos sociales, políticos y culturales, como las movilizaciones estudiantiles de los años 2006 y 2011, de trabajadores en 2007, las movilizaciones ambientales contra mega proyectos energéticos en 2011 y 2012, las reivindicaciones históricas del pueblo-nación Mapuche, y los cuasi levantamientos ciudadanos de Calama, Magallanes, Aysén, Alhué, Dichato y Freirina desde 2010.

Estos análisis colocan, por lo general, su atención -empírica- en las reuniones contestatarias, definidas como "asambleas públicas visibles en las que intereses en conflicto están claramente en juego" 26 , tomando como evidencias significativas, las formas de acción más notorias y disponibles para la observación, como las marchas, manifestaciones, paralizaciones, ocupaciones, huelgas o jornadas de movilización, que a menudo están superpuestas en un mismo evento.

Evidentemente, estas interpretaciones aportan valiosos elementos para una comprensión de los fenómenos contestatarios, así como de sus impactos sociales, políticos y culturales. Sin embargo, se observa una escasez de trabajos dedicados al análisis de una acción que aparece como inherente a estos eventos, que ha persistido en el tiempo y que, de cuando en cuando, adquiere relevancia propia: se trata de lo que denomino acción encapuchada. A diferencia del fenómeno conocido como los black blocs en Europa y Estados Unidos, que

\footnotetext{
${ }^{25}$ Mario Garcés, El despertar de la sociedad. Los movimientos sociales en América Latina y Chile, Santiago, LOM Ediciones, 2012; Albereto Mayol, Carla Azócar, "Politización del malestar, movilización social y transformación ideológica: el caso "Chile 2011"”, Polis, Revista de la Universidad Bolivariana 10: 30, 2011, 163-184; Carlos Durán, "El acontecimiento estudiantil y el viraje del proceso sociopolítico chileno", Revista OSAL, XIII: 3, 2012, 39-59.

${ }^{26}$ Charles Tilly, From Mobilization to Revolution, New York, Random House-McGraw-Hill Publishing Co, 1978,8 .
} 
han sido objeto de una nutrida gama de interpretaciones ${ }^{27}$, la acción encapuchada en Chile, si bien suele aparecer en distintos análisis, no constituye un foco de reflexión y ha sido destacado más como un fenómeno marginal, y las más de las veces negativo, de la contestación social. El tratamiento al respecto se ha dado "con la superficialidad que dan los prejuicios sobre este tema. Pareciera que la necesidad ética de condenar la violencia a priori, provocara que no se pudiera estudiar en profundidad sus motivaciones, dinámicas internas y causas profundas ${ }^{28}$. En este sentido, las y los encapuchados en Chile, normalmente, serían vándalos minoritarios ${ }^{29}$, formarían parte de "un "juego perverso" entre carabineros y encapuchados, lo que ya no es parte de la manifestación" 30 , serían grupos especializados en tácticas violentas "que esconden su rostro durante las protestas" $31 \mathrm{o}$, incluso, "provocadores enmascarados" 32 .

Otro acercamiento, también tangencial, se refiere a las formas de criminalización de la protesta. Destaca la lógica de "contabilidad del desastre" que hace la prensa sobre esta acción, la idea de que los encapuchados debilitan los movimientos sociales y justifican leyes represivas, o la relación naturalizada entre jóvenes y violencia provocada por los medios, entre otros ${ }^{33}$. También se encuentran reflexiones centradas en analizar la violencia política de las principales organizaciones armadas durante y después de la dictadura en Chile ${ }^{34}$, de la historia de levantamientos populares que desbordan la institucionalidad y que terminan en intervenciones militares para restaurar la institucionalidad liberal ${ }^{35} \mathrm{O}$, la relación que existe entre dos tipos de violencia, una contestataria, la otra institucional,

27 David Graeber, "The New Anarchists" New Left Review 13: 5, 2002, 66-78; Francis Dupuis-Déri, "The Black Blocs Ten Years after Seattle. Anarchism, Direct Action, and Deliberative Practices" Journal for the Study of Radicalism 4: 2, 2010, 45-82; Valerio D'Angelo, "Violencia contra violencia. Un análisis de la táctica "Black Bloc"”, Revista Española de Ciencia Política 36, 2014,13-33; Juris, op. cit.

${ }^{28}$ Contreras, op. cit., 2005, 211.

${ }^{29}$ Nicolás Somma, "Protestas y conflictos en el Chile contemporáneo: quince tesis para la discusión", Rodrigo Araya, Florencio Ceballos (eds.), Conflictos, controversias y disyuntivas, Santiago, Ediciones Abierta, 2017, 37-86, 73.

${ }^{30}$ Tamara Ramos, "Representaciones sociales de manifestantes sobre la interacción con Carabineros de Chile en las manifestaciones. Hacia una teoría fundada", Revista Némesis XI, 2014, 31-44, 39.

${ }^{31}$ Rodrigo Medel, Nicolás Somma, “¿Marchas, ocupaciones o barricadas? Explorando los determinantes de las tácticas de la protesta en Chile”, Política y gobierno XXIII: 1, 2016, 163-199, 178.

32 Abby Kerfoot, "Inequality, Organization, and Change in Chile: How Students Mobilized a Nation Around the Cause of Education Reform", The Washington University International Review, IV, 2015, 8-15.

${ }_{33}$ Oscar Aguilera, "Medios de comunicación en Chile, movimientos juveniles y políticas de la visibilidad", Comunicação, Mídia e Consumo 5: 14, 2008, 55-68; Guillermo Rivera, Karol Morales, Javiera Pavez, "La criminalización de los movimientos sociales: un análisis discursivo sobre la retórica que construye la ley antiencapuchados en Chile", Revista de estudios cotidianos 4: 1, 2016, 92-116; Raúl Zarzuri, "Jóvenes, violencia y medios de comunicación", Revista da Associação Nacional dos Programas de Pós-Graduação em Comunicação| E-compós, 11: 3, 2008 1-23.

${ }^{34}$ Igor Goicovic, "Temas y debates en la historia de la violencia política en Chile", Contenciosa, II: 3, 2014, $1-16$.

${ }^{35}$ Gabriel Salazar, La violencia política popular en las 'Grandes Alamedas'. La violencia en Chile 1947-1987 (Una perspectiva histórico popular), Santiago, LOM Ediciones, 2006 [1990]. 
siendo la segunda fuente de amenaza y generadora de miedo en quienes cuestionan el orden social ${ }^{36}$.

En todos los casos, las referencias al fenómeno de acción encapuchada ocupa espacios subordinados como dimensión de análisis. Tamara Contreras e Inés Pousadela son de las pocas que realizan un tratamiento más profundo en torno a este fenómeno de la violencia en las protestas, y de los enfrentamientos entre la policía y los encapuchados. Contreras, cuyo análisis se centra en la década de 1990 y principios de los 2000, se aboca a develar qué hay detrás de las protestas violentas, y cuáles son los sujetos que emergen durante la fecha simbólicamente significativa del 11 de septiembre. Ella demuestra que las principales motivaciones son el rescate de una memoria no oficial, que implicó el sacrificio de luchadores anónimos, la lucha contra un sistema económico y político, una expresión de rabia acumulada, y una violencia callejera entendida como expresión legítima frente a la violencia cotidiana del Estado. Además, que esta acción es llevada a cabo por jóvenes pobladores y estudiantes desadaptados, explotados y marginados ${ }^{37}$.

Según Pousadela, que se concentra en las movilizaciones estudiantiles de 2011-2012, los enfrentamientos entre encapuchados y policía se originan sea porque la policía interviene para dispersar o desalojar, porque su sola presencia invoca la violencia, o porque los encapuchados toman ventaja de la presencia policial para iniciar enfrentamientos. Con todo, los describe como jóvenes violentos enmascarados, "víctimas [casualties] de una sociedad excluyente" 38 . Si Pousadela se concentra en los contextos en que se origina un enfrentamiento violento entre encapuchados y policía, además de limitarlo a la fase final de las movilizaciones, en su caso, estudiantiles, y Contreras se concentra en lo que hay detrás de las protestas violentas en la década de 1990 y principios de 2000, concentrándose en los sujetos y las motivaciones, aquí me voy a concentrar en la dinámica de esta acción y de sus interacciones a lo largo de toda una movilización en el Chile contemporáneo. Además, si ambas autoras observan que, si bien los encapuchados pueden ser parte de los actores movilizados, pero no responden necesariamente a las organizaciones convocantes, aquí me voy a concentrar en cómo sus performatividades adquieren un carácter ritual que transmite valores e identidades significativas para el conjunto de manifestantes y de adversarios.

Como se ve, salvo excepciones, la acción encapuchada ha sido abordada de modo marginal en las reflexiones académicas. Ya sea como epifenómeno de manifestaciones masivas, como instrumentalización mediática o política para criminalizar la protesta, o en la relación entre violencia estatal y social-popular, su análisis no ha sido el foco de atención, más allá de las valiosas contribuciones realizadas en otros ámbitos de la protesta y la movilización social. En este artículo pretendo situar en el centro de la reflexión este

\footnotetext{
${ }^{36}$ Isabel Piper, "Violencia política, miedo y amenaza en lugares de memoria", Athenea digital. Revista de pensamiento e investigación social, 15: 4, 2015, 155-172.

${ }^{37}$ Contreras, op. cit., 2005.

${ }^{38}$ Inés Pousadela, "Protest and Proposal, Participation and Representation: the Chilean Student Movement, 2011-12”, Development in Practice 23: 5-6, 2013, 685-700, 696.
} 
fenómeno, describiendo sus dinámicas, sus performatividades y sus dimensiones simbólico-rituales, para comenzar a llenar ese vacío de reflexión.

\section{La acción encapuchada en el marco de una situación contestataria: marcha del primero de mayo clasista y combativo}

En esta sección voy a describir el fenómeno de la acción encapuchada en el tercer espacio nombrado más arriba, es decir, en su articulación en los intersticios de una manifestación. En este caso, me centro en la marcha del Primero de Mayo Clasista y Combativo, que es donde se pueden observar mejor las interacciones entre encapuchados y el resto de los manifestantes, así como con su adversario, representado en la policía, e identificado con el sistema. Esta marcha es relevante puesto que tradicionalmente, la Central Unitaria de Trabajadores (CUT) era la única que convocaba a la manifestación del primero de mayo, pero debido a su tendencia negociadora y conciliadora con gobiernos y empresarios, algunas organizaciones y sindicatos, criticando a la CUT e identificándose como clasistas y combativos, se escindieron y se conformaron en el Comité de Iniciativa por la Unidad Sindical (CIUS), primero convocando a contramarchas, luego a concentraciones alternativas, y desde hace algunos años, a una marcha paralela, que es donde se concentran las organizaciones y posiciones más radicales de las izquierdas contemporáneas de Chile.

\section{La marcha como protesta estandarizada.}

El domingo primero de mayo de 2016 se convocó a dos marchas en Santiago para conmemorar el Día Internacional del Trabajo. Una, desde la plaza Los Héroes, en la intersección de Alameda y Panamericana, se dirigiría hacia el oriente hasta calle Portugal con Alameda, fue convocada por la CUT. La otra, a dos cuadras al poniente, en avenida Brasil con Alameda, se dirigiría hacia el poniente hasta calle Matucana, convocada por el CIUS. En esta última, denominada Primero de Mayo Clasista y Combativo, se concentran las izquierdas más radicales del escenario social y político contemporáneo, mientras que en la convocada por la CUT asisten los partidos y movimientos de la Nueva Mayoría, coalición política del entonces gobierno de Michelle Bachelet. Es la manifestación de carácter clasista, combativa y en lucha, la que adquiere relevancia para este artículo, pues es aquí donde se despliega con intensidad la acción encapuchada, mientras que, en la otra marcha, este fenómeno está siendo reprimido por las propias organizaciones manifestantes.

La manifestación estaba convocada a las 10:00 horas. Esa mañana cayó una inesperada lluvia, y estaba más frío que en días anteriores, así que los manifestantes llegaban a cuentagotas, y se vio menor convocatoria que otros años. Luego de esperar que se reuniera una cantidad apropiada de manifestantes, aproximadamente a las 11:00 comenzó el desplazamiento hacia el punto del acto. De las cerca de quinientas agrupaciones que finalmente se congregaron, se podía observar una variopinta composición, tanto respecto del origen social (sindical, estudiantil, político, entre otros), como en lo ideológico, aunque 
todas evidentemente de izquierdas. Destacan el Sindicato de Oficios Varios, el Movimiento por Amnistía y Derechos Fundamentales (Movadef), la Confederación General de Trabajadores, la Unión Clasista de Trabajadores, la Federación Comunista libertaria, el Frente Patriótico Manuel Rodríguez, el Comité de Unidad Revolucionaria (CUR), la Alzada Acción Feminista Libertaria, el Movimiento Popular Guachuneit, la Organización de Padres y Apoderados Movilizados (OPAM), la Federación Nacional de Pobladores (Fenapo), el Movimiento de Pobladores Ukamau, o el Movimiento de Trabajadores Clotario Blest, tratándose de organizaciones que repiten asistencia todos los años etnografiados.

La marcha transcurre de un modo estandarizado durante las doce cuadras aproximadas de trayecto: grupos organizados en colectivos, sindicatos $u$ otros caminan agrupados, tras un lienzo transversal en el que están escritos el nombre de la agrupación y sus principales reivindicaciones. Tras el lienzo caminan otros manifestantes llevando pancartas o banderas alusivas a esas demandas. Durante el trayecto, corean consignas ligadas a la situación posicional de la organización (aumento de sueldos, pensiones dignas, contra despidos, por viviendas dignas, entre otros), y otras de tipo más general, que pueden estar marcadas por la coyuntura (contra la corrupción o contra el gobierno) o por cuestiones de mayor alcance, como una asamblea constituyente, el cambio del sistema de pensiones, o aun por la revolución proletaria mundial. Además de estos grupos, observo también una variedad de agrupaciones realizando performances teatrales y expresivas, principalmente batucadas y comparsas, que pueden formar parte de grupos determinados, o que son en sí mismos grupos diferenciados que se manifiestan.

En general, esta dinámica se mantiene estable, salvo algunos momentos en que se ven situaciones más espectaculares, como cuando cerca de la esquina de Libertad con Alameda varias organizaciones barriales, sindicales, estudiantiles y territoriales se detuvieron y, formando un círculo, algunos dirigentes enunciaron discursos reivindicativos, rodeados de bengalas rojas encendidas, lo que daba a la performance un carácter cuasi místico. $\mathrm{O}$ cuando otra agrupación, disfrazados con overoles y máscaras de colores, avanzaron en comparsa, cantando y bailando. También, se ven grupos de encapuchados que aparecen súbitamente, organizados en pequeños grupos, rayando muros, echando abajo semáforos o rompiendo basureros, para moverse y desaparecer también rápidamente. Finalmente, al llegar a la zona del acto, comienzan los discursos reivindicativos de los dirigentes, intercalados con bandas musicales. La atmósfera que prima entre los manifestantes es el respeto y tranquilidad, algunos escuchando y celebrando los discursos, los más, ignorándolos. El acto termina, como todos los años, entonando La Internacional por los altoparlantes.

Esta manifestación corresponde a un evento estandarizado de protesta, en tanto una reunión multitudinaria, identificada con asociaciones formales, que despliegan públicamente su valía, unidad, número y determinación, en apoyo de unas demandas bien 
definidas ${ }^{39}$. Un encuentro que tiene preparación previa, cuando el CIUS elabora la convocatoria, difundiéndola, preparando la logística (escenario, sonido y amplificación, pancartas y carteles, etc.), solicitando permisos a las autoridades, y a la que le siguen evaluaciones, análisis de coyuntura, y proyecciones, entre otros. Se trata del modelo de manifestación más común del repertorio de contestación en Chile, que es lo analizado por gran parte de los estudios. Sin embargo, en los intersticios de la manifestación, se observa la cara menos estudiada, que son los enfrentamientos y la interacción de los encapuchados y la policía, lo que constituye la acción encapuchada.

\section{La acción encapuchada como dinámica de enfrentamiento violento}

Una vez llegados al lugar del acto, un grupo de alrededor de treinta encapuchados se concentró en la esquina de Chacabuco y Alameda, a una cuadra al oriente del escenario, por el lado norte de Alameda, y comienza a echar abajo la señalética pública, saca las bolsas de basura para quemarlas en medio de la calle, y busca elementos adecuados para erigir y mantener una barricada. La imagen es un poco inquietante, porque si el objetivo de una barricada es parapetarse e impedir el paso del enemigo, esta trinchera difícilmente va a obstaculizar el avance del "zorrillo" y los "guanacos", vehículos blindados con que opera la policía lanzando gas y agua tóxicos en las manifestaciones. Tampoco va a resistir el avance de los piquetes de policías de fuerzas especiales. Sobre todo, considerando que desde la misma barricada se puede observar, a unas tres cuadras hacia el norte, más de un centenar de carabineros con sus trajes antidisturbios (casco, chaleco antibalas, botas militares, protectores de rodilla, canilla, antebrazo y cuello, armas y escudos), acompañados de zorrillos, guanacos, furgones, camiones y motos. Esta situación hace recordar cuando Engels comentaba que las barricadas tenían una eficacia más moral que material ${ }^{40}$, ya que las condiciones de lucha se hacen mucho más desfavorables para los insurrectos, que para las tropas.

Pero los encapuchados parecen no importarles esta desigual distribución de fuerzas, y la treintena comienza a gritar consignas a favor de una revolución, del derrumbe del sistema, contra el gobierno y el aparato represor. También, algunos rayan consignas en los muros cercanos, y otros se concentran en mantener prendida la barricada con la materialidad disponible.

Desde donde me encuentro, observo que, al mismo tiempo que se despliega esta barricada, y los encapuchados corean, rayan, y la mantienen encendida, en la parte trasera de la marcha, a unas cuatro cuadras, el enfrentamiento ya está en acto. Lo que al principio eran escaramuzas intersticiales aisladas de pequeños grupos de encapuchados lanzando piedras a la policía, intentando romper las cortinas metálicas de algún negocio, quemando

39 Charles Tilly, Popular Contention in Great Britain, 1758-1834, Boulder, Paradigm Publishers, 2005 [1995].

${ }^{40}$ Federico Engels, "Introducción a Marx. Las luchas de clase en Francia de 1848-1850”, Karl Marx, Federico Engels, Obras Escogidas, Moscú, Progreso, 1977 [1891], 117. 
basureros o destrozando paraderos de micros, comienza a concentrarse al final de la misma al momento en que los manifestantes se van acercando al lugar del acto. Las provocaciones cruzadas, tanto de encapuchados como de policías, comenzaron en esa parte, y la policía responde intensiva, y extensivamente, lanzando indiscriminadamente chorros de agua tóxica y de gas, haciendo correr al conjunto de los manifestantes que se encuentran a su alcance. Desde mi posición veo cómo el guanaco lanza el chorro, y cómo también se empieza a propagar el gas del zorrillo por sobre las cabezas de los manifestantes. También puedo advertir que una cantidad considerable de manifestantes comienzan a acercarse hacia el lugar del acto, intentando alejarse, algunos más calmos y otros más apurados, del foco de enfrentamiento. No obstante, pareciera que la mayoría de manifestantes sabe cómo comportarse en estas situaciones, y conoce qué conductas son más eficaces, ya que a pesar de que el guanaco lanza un chorro tóxico, y que la policía se encuentra cerca, pocos corren despavoridos, y tampoco observo muchas expresiones de pánico en los rostros o en los cuerpos de quienes se acercan al lugar en que me encuentro, cerca de la barricada.

Pasados unos minutos, los guanacos y zorrillos avanzan acercándose a la esquina en que nos encontramos, siguiendo a los encapuchados, varios de los que llegan a la barricada. Ahora los encapuchados comienzan a lanzar piedras y otros objetos contundentes, incluso una molotov, gritando consignas contra el sistema, y contra la policía, intentando mantener la barricada. Cuando la policía se acerca de modo excesivo, los encapuchados se dispersan entre los manifestantes para volver a reagruparse en otro intersticio, y volver a armar otra barricada o enfrentarse a la policía. El ambiente, que en la barricada era de una especie de euforia, se transforma en otro más parecido a la confusión. Si la barricada funciona como un espacio que agrupa a manifestantes encapuchados, sin capuchas, incluso varios fotógrafos, cuando se acerca la policía todos se dispersan, y los encapuchados desaparecen, quedando sola. Si al principio lo que primaba era el olor a objetos quemándose, entre papeles, pintura, palos y sobre todo plástico, ahora prima el olor picante de los gases con químicos de la policía, quedando varios con los ojos llorosos, y algunos tosiendo por el efecto lacrimógeno. Hay quienes portan limón o amoníaco, los usan y les prestan a otros para despejar las vías respiratorias. En esta esquina, la confusión se hace más notoria y muchos manifestantes se alejan cuando el guanaco llega. Pero de todos modos puedo ver desde mi nueva posición, a media cuadra hacia el norte por Chacabuco, que muchos manifestantes siguen merodeando bastante tranquilamente. Algunos pasan por el lado del guanaco, de los camiones de policía, incluso gente se queda a mirar al lado de los piquetes de policía que se sitúan en la esquina, una vez apagada la barricada.

El enfrentamiento y los ensayos de barricada siguen en otras esquinas, pero cada vez se van haciendo más esporádicos. Mientras, en el escenario, los oradores intentan volver a la calma para terminar el acto. Los enfrentamientos vuelven a ser escaramuzas y puedo ver, ahora de vuelta en la Alameda, piedras lanzadas y chorros de guanaco en varios sitios, como antes del acto. La barricada inicial, la de Chacabuco con Alameda, parece un recuerdo sobre el que pasan algunos manifestantes que se van retirando del acto. Todavía quedan numerosos manifestantes, muchos escuchando a los oradores o a las bandas, otros 
haciendo otras cosas, como comprando parches, chapas, posters, o aun comidas o bebidas de los comerciantes que se colocan a lo largo de la manifestación. Los encapuchados, por su parte, transitan entre medio de los manifestantes, en grupos pequeños, de un lugar a otro, caminando rápido, para desaparecer entre el gentío. De vez en cuando le lanzan objetos a la policía, especialmente al guanaco que por su tamaño es más fácil apuntarle. Si bien el ambiente vuelve a ser relativamente calmo, aparecen otros focos de enfrentamiento o escaramuzas. Estas, no obstante, son cada vez más esporádicas, y las escaramuzas cada vez más cortas. A medida que la manifestación se va terminando, y los manifestantes se retiran, se va terminando también la acción encapuchada.

\section{Hacia un análisis de la acción encapuchada: eficacia simbólica y transmisión cultural.}

Si las escaramuzas, la barricada y el enfrentamiento, son performances violentas desiguales entre encapuchados y policía, porque los magros materiales con que se enfrentan los primeros no pueden hacer frente a vehículos blindados, gases tóxicos, armas, y tecnología de los segundos, ¿Por qué sigue persistiendo este fenómeno de acción encapuchada, y se siguen levantando barricadas, si su eficacia material está condenada al fracaso? La persistencia de este fenómeno devela que es más factible interpretarlo como una secuencia de actos cuya eficacia opera más en el campo de lo simbólico que de lo material. En este sentido, parece relevante observar la acción encapuchada como una performance inserta en un proceso ritual, en el que su eficacia se daría más porque comunica valores y cultura, tanto endógena como exógenamente, que porque tenga la capacidad de derrocar al sistema que enfrenta.

La performance como despliegue ritual, es un comportamiento aprendido y ensayado que busca mostrar a través del hacer, subrayando una acción para quienes la observan ${ }^{41}$. Una performance es, por tanto, un comportamiento corporalizado que está en realización ${ }^{42}$. Observando el despliegue de la acción encapuchada, vemos que sus dinámicas se repiten, y transmiten significados. Más allá de las diferencias contingentes de cada año, lo cierto es que se trata de una secuencia relativamente estandarizada de actos conocidos por todos, cuyo carácter simbólico predomina. Esquemáticamente, se pueden distinguir las siguientes fases. Primero, los encapuchados se encapuchan. Por banal que parezca esta aseveración, ellos no llegan a la manifestación con sus caras cubiertas, ni tampoco blandiendo espray o molotovs, sino como cualquier manifestante. Ellos se cubren el rostro, mostrando un rostro 'otro', al interior de la manifestación, y esta puesta en escena, en tanto transformación corporal y estética, opera como diferenciadora. El acto estético de ponerse una polera que deje sólo los ojos al descubierto, implica una conducta simbólica que distingue un "nosotros" encapuchado, y un "otros", que son los manifestantes no encapuchados, como también los adversarios. Este primer momento separa al

\footnotetext{
${ }^{41}$ Schechner, op. cit., 2013 [2002]; 2005 [1988]

${ }^{42}$ Taylor, op. cit., 2003, 76
} 
encapuchado del resto, abriendo una brecha, que establece tanto una frontera identitaria como el constituir un "nosotros".

Luego, se observa que las escaramuzas fungen como una especie de preparación para el momento central de acción encapuchada, constituido por las barricadas y el enfrentamiento violento con la policía. Independientemente de su duración (en 2016 duró escasos minutos, pero con varios focos, pero en 2018 duro alrededor de una hora y media, con una sola barricada central), aquí comienza lo que Gluckman ${ }^{43}$ llama la manifestación catártica de tensiones sociales mediante el rito de rebelión. Este enfrentamiento violento y catártico, además, implica entrar en una communitas: un momento caracterizado por la indistinción, un estar "dentro y fuera de la estructura social secular"44, como un umbral en el que las clasificaciones cotidianas dejan de tener sentido. Durante la barricada, los encapuchados se concentran en prenderla, agrandarla, mantenerla, y defenderla. Como materialidad positiva, ella otorga densidad a una identificación endógena en tanto encapuchados, todos iguales y en comunión en favor de algo, comunicándose a través de sus actos, valores y cultura. Pero también el enfrentamiento implica una interacción conflictiva, exógena, que es causar daño material y defenderse de los ataques policiales. En este sentido, el enfrentamiento con la policía simboliza al sistema que los encapuchados pretenden derrocar, comunicando también valores y transmitiendo cultura. La policía, por su parte, para resguardar un orden, opera de modo correctivo con la finalidad de recomponer una situación anterior. Esta interacción exógena permite también darle espesor a su identificación como encapuchados frente a un adversario común, porque establece una frontera entre un "nosotros" y un "ellos".

Finalmente, concluido el enfrentamiento y extinguida la barricada, los encapuchados vuelven a formar parte de los manifestantes, primero despojándose de los elementos materiales que sirvieron para el enfrentamiento (lanzando su último objeto contundente, prendiendo su última bomba molotov, alejándose de la zona de enfrentamiento), y, sobre todo, sacándose la capucha. Desde ese momento, los encapuchados ya no se distinguen del conjunto de los manifestantes, reincorporándose a lo que resta de la manifestación.

La acción encapuchada puede concebirse como una unidad de procesos sociales, no armónicos, que emergen en situaciones conflictivas, como "la realización [performance] de una secuencia compleja de actos simbólicos" 45 . Es decir, como dramas sociales y como procesos rituales. En este sentido, las fases descritas más arriba son susceptibles de comprenderse si se las observa como actos simbólicos de un proceso ritual en particular: como rito de rebelión. La brecha o separación entre encapuchados y manifestantes; la crisis o communitas de los encapuchados en interacción violenta con la policía; la acción correctora de la policía y; la reintegración de los encapuchados al conjunto de manifestantes, es puesta en escena a través de la escenificación de performances como actos simbólicos específicos que se repiten: la capucha, la molotov, la barricada, la piedra,

\footnotetext{
${ }^{43}$ Gluckman, op. cit., 1963 [1954].

44 Turner, op. cit., 1988 [1969], 103.

45 Turner, op. cit., 1985, 180.
} 
no sólo constituyen la materialidad del proceso ritual, sino que también ese despliegue transmite una serie de valores simbólicos para quienes participan, observan, y también reprimen. Se trata de conductas escenificadas que significan algo, poniendo de manifiesto a través de esa escenificación, conflictos y tensiones fundamentales de la sociedad, y que están "inseparablemente relacionadas a un proyecto de rebelión" 46.

En términos de sus dinámicas performativas y las interacciones de su despliegue, la acción encapuchada permite ser observada como un proceso ritual. En esto, la acción encapuchada no se diferencia mayormente del fenómeno de los black bloc en Europa o Estados Unidos ${ }^{47}$, ya que ambas acciones despliegan conductas basadas en una violencia performativa, enfrentándose con la policía, erigiendo barricadas y destruyendo mobiliario asociado al poder. También ambas violencias performativas son una forma de interacción que, mediante sus actos, transmite "significados alternativos, valores e identidades [que] son producidas, encorporadas y comunicadas públicamente" 48 . Ambos, a través de una secuencia compleja de actos, comunican valores e identidades tanto al conjunto de manifestantes (endógeno), como hacia sus adversarios y el público general (exógeno), por lo que ambas acciones pueden ser entendidas, más que como una violencia sin sentido e irracional, como una forma cultural históricamente desarrollada de acción cargada de sentido ${ }^{49}$.

Pero ¿qué es lo que transmiten las performatividades ritualizadas de los encapuchados en Chile? Escuchando sus consignas, observando sus vestimentas y los rayados que los encapuchados plasman en los muros, se devela una primera pista del contenido simbólico que transmite dicho despliegue performativo, que trata de traer a la actualidad momentos heroicos de resistencia y de luchas populares en Chile. En particular, de la relevancia de las luchas durante la dictadura (1973-1990), donde la acción encapuchada busca actualizar la memoria de los 2.296 asesinados (Informe de la Comisión Nacional de Verdad y Reconciliación, 1991) y 28.459 torturados (Informe de la Comisión Nacional sobre Prisión Política y Tortura, 2005) por el régimen. Se escuchan, en particular, referencias a los hermanos Rafael y Eduardo Vergara Toledo, de 18 y 20 años respectivamente, militantes del Movimiento de Izquierda Revolucionaria (MIR), asesinados el 29 de marzo de 1985 por la policía. En este sentido, el ritual encapuchado se articula, tomando parte de su significado, con un momento particularmente conflictivo de la historia chilena, al dar cuenta de una oposición entre memorias rivales, operando, a través de sus actos, una suerte de activación de la memoria ${ }^{50}$. Esa memoria busca disputar la legitimidad de la memoria oficial, y sus significaciones son vehiculadas, a través del acto de ofrecer el cuerpo, por la acción encapuchada, hacia el resto de los manifestantes presentes. La acción

\footnotetext{
${ }^{46}$ Schröter, op. cit., 2004, 47.

${ }^{47}$ Graeber, op. cit., 2002; Juris, op. cit., 2005; Dupuis-Deri, op. cit., 2010 ; D’Angelo, op. cit., 2014.

48 Jeffrey Juris, "Embodying Protest: Culture and Performance within Social Movements", Britta Baumgarten, Priska Daphi, Peter Ullrich (eds.), Conceptualizing culture in social movement research, London, Palgrave Macmillan, 2014, 227-247, 227.

49 Juris, op. cit. 2005.

${ }^{50}$ Jelin, op. cit. 2005
} 
encapuchada, busca crear memoria contrahegemónica activada hacia el conjunto de los manifestantes.

En segundo lugar, la acción encapuchada en Chile, por el mismo movimiento de estar ligada a la activación de una memoria de resistencias, tiene también una intencionalidad que está articulada a un proyecto de rebelión social y política, lo que denota su relevancia en el campo de las luchas sociales en Chile. Las provocaciones y el enfrentamiento directo con la policía, fungen como una contestación contra la autoridad y contra la institucionalidad. Porque la acción encapuchada, como proceso ritual, se enfrenta a esa autoridad sin importar la tendencia política del gobierno, pues se trata de la facción más radical de una izquierda desconfiada que, a pesar de estar excluida, subsiste en formas de organización heterodoxa ${ }^{51}$. En este sentido, el simbolismo que se pone en acto mediante la capucha y la performatividad expresada en el acto de enfrentarse la autoridad, más que confirmar estratégicamente su presencia, comunica un proyecto de rebelión social, proyecto que no es necesariamente el mismo para todas y todos los encapuchados. Así, los encapuchados se tornan ellos mismos unos medios de expresión que dan cuenta de la violencia, e irracionalidad escondida en los códigos dominantes, y es por medio de lo que los encapuchados hacen y de cómo lo hacen que dan cuenta que un proyecto distinto al dominante es posible52. Develar cuáles son esos proyectos, si tienen sentidos o articulaciones equivalenciales, en función de cada grupo encapuchado, y desentrañar las estructuras de esas significaciones, su campo social y sus alcances, es tarea de futuras investigaciones.

El simbolismo en acto de los encapuchados comunica significados específicos y relevantes, tanto para los manifestantes como para los adversarios. Si en su dinámica general puede ser equivalente al fenómeno black bloc, es a nivel de contenido simbólico donde difieren significativamente ambos fenómenos, ya que mientras los black blocs están vinculados al movimiento anti-globalización y su práctica no siempre entraña violencia, pudiendo combinarse con tácticas de grupos carnavalescos, con asistencia médica o con protección ${ }^{53}$, los encapuchados no se articulan con otros grupos, y articulan, a través de su performatividades, memoria contrahegemónica y proyecto histórico de rebelión.

\section{Conclusiones}

A través del estudio de la secuencia de actos y de performances que despliegan los encapuchados en el marco de la manifestación del Primero de Mayo Clasista y Combativo en Santiago de Chile, este artículo ha argumentado que dicha acción puede ser mejor comprendida como un proceso ritual cuya eficacia se sitúa en el campo de lo simbólico, más que en el campo de lo material. En tanto proceso, vimos que su dinámica pasa por las

\footnotetext{
${ }^{51}$ Rafael Agacino, "Hegemonía y contra hegemonía en una contrarrevolución neoliberal madura. La izquierda desconfiada en el Chile post-Pinochet", Consejo Latinoamericano de Ciencias Sociales - CLACSO. Grupo de Trabajo Hegemonías y emancipaciones. Caracas, enero 30-31, 2006.

${ }^{52}$ Melucci, op. cit. 1985

${ }^{53}$ D'Angelo, op. cit., 2014; Juris, op. cit., 2005; Dupuis-Deri, op. cit., 2010.
} 
cuatro fases típicas del drama social, que son la separación del grupo, la indistinción o communitas expresada en el enfrentamiento violento, la acción correctiva de la policía, y una reincorporación, más que cisma, una vez terminada la manifestación. La persistencia de este fenómeno y sus dinámicas dan cuenta, además, de su relevancia como comunicador de significados, tanto hacia el conjunto de los manifestantes (endógeno), como hacia el adversario y la población general (exógeno).

En sentido endógeno, la acción encapuchada pone de manifiesto, a través de la activación de una memoria contrahegemónica, las luchas y resistencias populares contra una dictadura autoritaria. Se trata de traer al presente, a través del acto de poner el cuerpo frente a la policía, los sacrificios de todos los desaparecidos, torturados y asesinados. En sentido exógeno, la acción encapuchada pone de manifiesto un proyecto de rebelión radical contra la institucionalidad política, a través de la serie de escenificaciones que operan durante el enfrentamiento violento con la policía. La acción encapuchada, más que intentar derrocar el sistema en su dinámica confrontativa, está expresando al adversario y a la sociedad, a través del cómo hacen lo que hacen, un proyecto de transformación posible.

Lo recién presentado nos empuja a reflexionar más profundamente en torno a la relevancia de un fenómeno que se resiste a desaparecer de las manifestaciones contestatarias en Chile. En este artículo propuse un análisis que subraya la relevancia en términos rituales, performativos y simbólicos, de la acción encapuchada, atendiendo al cómo, a través de sus actos, los encapuchados comunican significados y valores sociales relevantes a la sociedad. En este sentido, cobran relevancia las palabras de Contreras, para quien "En estos contextos de lucha frontal contra sus enemigos, principalmente la policía y el capital, estos jóvenes se alinean bajo la capucha y el fuego, dos elementos simbólicos y de representación de los espacios de acción más radical de la juventud rebelde (de los 90...). La capucha como símbolo de radicalidad y confrontación, y el fuego como elemento de lucha, expresado en las barricadas y las molotovs" 54 . Este enfoque permite superar la tendencia a ver el fenómeno encapuchado simplemente como actos marginales de individuos o grupos aislados, vándalos o provocadores que emplean una violencia sin sentido. Por el contrario, permite observar este fenómeno articulándolo con la historia y trayectorias de las luchas sociales en Chile, cuyas dinámicas performativas tienen un carácter simbólico cargado de sentido, abriendo vías interpretativas, poco exploradas, sobre el rol que lo simbólico juega en las protestas y manifestaciones contestatarias contemporáneas.

\footnotetext{
${ }^{54}$ Contreras, op. cit. 2005, 223-224.
} 


\section{Bibliografía.}

\section{Fuentes impresas.}

Contreras, Tamara, "Los "11" en democracia: ¿vandalismo anómico o nueva radicalidad política juvenil?”, Zarzuri, Raúl, Ganter, Rodrigo (comp.), Jóvenes: la diferencia como consigna. Ensayos sobre la diversidad cultural juvenil, Santiago, Ediciones CESC, 2005, 211-238.

Engels, Federico, "Introducción a Marx. Las luchas de clase en Francia de 18481850”, Marx, Karl, Engels, Federico, Obras Escogidas, Moscú, Progreso, 1977 [1891].

Garcés, Mario, El despertar de la sociedad. Los movimientos sociales en América Latina y Chile, Santiago, LOM Ediciones, 2012.

Geertz, Clifford, La interpretación de las culturas, Barcelona, Gedisa, 2003 [1973].

Gluckman, Max, "Rituals of Rebellion in South-East Africa", Max Gluckman, Order and Rebellion in Tribal Africa, London, Routledge, 1963 [1954].

Graeber, David, Fragments of an Anarchist Anthropology, Chicago, Prickly Paradigm Press, 2004.

Grau, Olga, "El encapuchamiento de la memoria", Richard, Nelly (Ed.), Políticas y Estéticas de la Memoria, Santiago, Editorial cuarto Propio, 2000, 199-204.

Imilan, Walter, "Performance", Dhan Zunino, Guillermo Giucci, y Paola Jirón (eds.), Términos clave para los estudios de movilidad en América Latina, Buenos Aires, Biblos, 2018, 147-152.

Juris, Jeffrey, "Embodying Protest: Culture and Performance within Social Movements", Britta Baumgarten, Priska Daphi, Peter Ullrich (eds.), Conceptualizing culture in social movement research, London, Palgrave Macmillan, 2014, 227-247.

Rosas, Pedro, "Luka: Subversivo y rebelde de la transición chilena. Un ejercicio de Historia Oral y memoria", Zarzuri, Raúl, Ganter, Rodrigo (Comp.). Jóvenes: la diferencia como consigna. Ensayos sobre la diversidad cultural juvenil, Santiago, Ediciones CESC, 2005, 239-261.

Rosas, Pedro, Rebeldía, subversión y prisión política. Crimen y castigo en la transición chilena, Santiago, LOM Ediciones, 2004.

Salazar, Gabriel, La violencia política popular en las 'Grandes Alamedas'. La violencia en Chile 1947-1987 (Una perspectiva histórico popular), Santiago, LOM Ediciones, 2006 [1990].

Schröter, Susanne, "Rituals of Rebellion - Rebellion as Ritual: A Theory Reconsidered", Jens Kreinath, Constance Hartung, and Annette Deschner (eds.) The Dynamics of Changing Rituals. The Transformation of Religious Rituals within Their Social and Cultural Context, New York, Peter Lang Publishers, 2004, 41-57.

Taylor, Diana, The Archive and the Repertoire. Performing Cultural Memory in the Americas. Durham, Duke University Press, 2003.

Tilly, Charles, From Mobilization to Revolution, New York, Random House-McGrawHill Publishing Co, 1978.

Tilly, Charles, Popular Contention in Great Britain, 1758-1834, Boulder, Paradigm Publishers, 2005 [1995].

Turner, Victor, El proceso ritual. Estructura y antiestructura, Madrid, Editorial Taurus, 1988 [1968]. 
Turner, Victor, On the Edge of the Bush. Anthropology as Experience, Tucson, AZ, University of Arizona Press, 1985.

Zarzuri, Raúl, Contreras, Tamara, “Jóvenes y violencia. Los usos de la violencia y la construcción de la participación juvenil”, de la Fuente, Gloria, Contreras, Sergio, Paulo, Hidalgo, Sau, Julio (eds.), Participación y nuevos desafíos político-institucionales, Santiago, LOM, 2009, 113-148.

Zunino, Dhan, "Ritmo/ritmoanálisis", Dhan Zunino, Guillermo Giucci, y Paola Jirón (eds.), Términos clave para los estudios de movilidad en América Latina, Buenos Aires, Biblos, 2018, 161-170.

\section{Fuentes electrónicas y digitales.}

Agacino, Rafael, "Hegemonía y contra hegemonía en una contrarrevolución neoliberal madura. La izquierda desconfiada en el Chile post-Pinochet", Consejo Latinoamericano de Ciencias Sociales - CLACSO. Grupo de Trabajo Hegemonías y emancipaciones. Caracas, enero 30-31, 2006.

Aguilera, Oscar, "Medios de comunicación en Chile, movimientos juveniles y políticas de la visibilidad", Comunicação, Mídia e Consumo 5: 14, 2008, 55-68. [1992].

Bell, Catherine, Ritual Theory, Ritual Practice, Oxford, Oxford University Press, 2009

D'Angelo, Valerio, “Violencia contra violencia. Un análisis de la táctica "Black Bloc"', Revista Española de Ciencia Política 36, 2014,13-33.

Desai, Manisha, "The Possibilities and Perils for Scholar-Activists and ActivistScholars. Reflections on the Feminist Dialogues", Jeffrey Juris, Alex Khasnabish (eds.), Insurgent Encounters. Transnational Activism, Ethnography, $\mathcal{E}$ the Political, Durham, Duke University Press, 2013, 89-107.

Dupuis-Déri, Francis, “The Black Blocs Ten Years after Seattle. Anarchism, Direct Action, and Deliberative Practices" Journal for the Study of Radicalism 4: 2, 2010, 45-82

Durán, Carlos, “El acontecimiento estudiantil y el viraje del proceso sociopolítico chileno", Revista OSAL, XIII: 3, 2012, 39-59.

Goicovic, Igor, "Temas y debates en la historia de la violencia política en Chile", Contenciosa, II: 3, 2014, 1-16.

Gómez, Juan Carlos, Los encapuchados, actores anticapitalistas de la posmodernidad neoliberal, Rebelión, 2016, http://www.rebelion.org/noticia.php?id=213339.

Graeber, David, "The New Anarchists" New Left Review 13: 5, 2002, 66-78.

Jelin, Elizabeth, "Exclusión, memorias y luchas políticas", CLACSO, Estudios Latinoamericanos sobre cultura y transformaciones sociales en tiempos de globalización, Buenos Aires, CLACSO, 2005.

Juris, Jeffrey, "Violence Performed and Imaginated. Militant Action, the Black Bloc and the Mass Media in Genoa" Critique of Anthropology 25:4, 2005, 413-432. DOI: https://doi.org/10.1177/0308275X05058657.

Kerfoot, Abby, "Inequality, Organization, and Change in Chile: How Students Mobilized a Nation Around the Cause of Education Reform", The Washington University International Review, IV, 2015, 8-15. 
Le Breton, David, "Mauss et la naissance de la sociologie du corps", Revue du MAUSS 36: 2, 2010, 371-384. 2004 [1992].

Lefebvre, Henri, Rhythmanalysis. Space, time and everyday life, London, Continuum,

Mayol, Alberto, Carla Azócar, "Politización del malestar, movilización social y transformación ideológica: el caso “Chile 2011"”, Polis, Revista de la Universidad Bolivariana 10: 30, 2011, 163-184.

Medel, Rodrigo, Nicolás Somma, “¿Marchas, ocupaciones o barricadas? Explorando los determinantes de las tácticas de la protesta en Chile", Política y gobierno XXIII: 1, 2016, 163-199.

Melucci, Alberto, "The Symbolic Challenge of Contemporary Movements", Social Research 52: 4, 1985, 789-816.

Piper, Isabel, "Violencia política, miedo y amenaza en lugares de memoria", Athenea digital. Revista de pensamiento e investigación social, 15: 4, 2015, 155-172.

Pousadela, Inés, "Protest and Proposal, Participation and Representation: the Chilean Student Movement, 2011-12", Development in Practice 23: 5-6, 2013, 685-700.

Ramos, Tamara, "Representaciones sociales de manifestantes sobre la interacción con Carabineros de Chile en las manifestaciones. Hacia una teoría fundada", Revista Némesis XI, 2014, 31-44.

Rappaport, Joanne, “Beyond Participant Observation: Collaborative Ethnography as Theoretical Innovation", Collaborative Anthropologies 1, 2008, 1-31.

Restrepo, Eduardo, Etnografía. Alcances, técnicas y éticas, Lima, Fondo Editorial de la Universidad Nacional Mayor de San Marcos, 2018. [2002].

Richard Schechner, Performance Studies: An Introduction, London, Routledge, 2013

Richard Schechner, Performance Theory, New York, Routledge, 2005 [1988].

Rivera, Guillermo, Karol Morales, Javiera Pavez, “La criminalización de los movimientos sociales: un análisis discursivo sobre la retórica que construye la ley antiencapuchados en Chile", Revista de estudios cotidianos 4: 1, 2016, 92-116.

Somma, Nicolás, "Protestas y conflictos en el Chile contemporáneo: quince tesis para la discusión", Rodrigo Araya, Florencio Ceballos (eds.), Conflictos, controversias y disyuntivas, Santiago, Ediciones Abierta, 2017, 37-86.

Turner, Victor, "Symbolic Studies", Annual Review of Anthropology 4, 1975, 145-161.

Wilson, Monica, "Nyakyusa Ritual and Symbolism”, American Anthropologist 56:2, 1954, 228-241.

Zarzuri, Raúl, “Jóvenes, violencia y medios de comunicación”, Revista da Associação Nacional dos Programas de Pós-Graduação em Comunicação | E-compós, 11: 3, 2008, 1-23. 